Bio - grafía. Escritos sobre la Biología y su Enseñanza. ISSN 2027-1034

Edición Extraordinaria. p.p. 700 - 710

Memorias del IX Encuentro Nacional de Experiencias en Enseñanza de la Biología y la Educación Ambiental. IV Congreso Nacional de Investigación en Enseñanza de la Biología.

\title{
ARGUMENT ACIÓN PARA UN APRENDIZAJE SIGNIFICATIVO CRÍTICO SOBRE GENOMA HUMANO EN EDUCACIÓN BÁSICA SECUNDARIA
}

\author{
ARGUMENT FOR A CRITICAL MEANINGFUL LEARNING ON GENOME HUMAN IN \\ BASIC SECONDARY EDUCATION
}

\author{
Juan Diego Restrepo ${ }^{1}$
}

\section{RESUMEN}

Partidarios de la inclusión de problemáticas que se tejen alrededor del Genoma Humano en la enseñanza a menores de 16 años, y seguros de la factibilidad de hallar métodos apropiados para su enseñanza, resaltamos la importancia de las interacciones de los jóvenes de grado décimo con los maestros y sus pares, en la construcción de habilidades cognitivas, específicamente de estrategias argumentativas, que permitan hacer uso crítico de conocimientos.

Implementamos actividades pedagógicas, con las cuales pretendemos propiciar en los estudiantes un aprendizaje significativo crítico a través de las argumentaciones que los mismos construyen. Prestamos principal atención a los enunciados que están inscritos en los discursos orales, que emergen en el despliegue de las diferentes situaciones que hacen parte de la propuesta pedagógica.

En este sentido, los enunciados y las secuencias de enunciados son objeto de análisis, y pueden dar indicios de una aproximación de los estudiantes al aprendizaje significativo crítico. Iniciamos los mismos dirigiendo la mirada a los elementos del modelo toulminiano, que incorporan los estudiantes cuando elaboran sus argumentaciones. Posteriormente prestamos atención a aquellos enunciados en los que se pueden identificar cuestiones de orden epistemológico con tendencia reduccionista u holística, que explicitan los estudiantes sobre Genoma Humano.

\section{PALABRAS CLAVE}

Aprendizaje significativo crítico, genoma humano, argumentación, tendencia reduccionista, tendencia holística, asunto sociocientífico.

\section{ABSTRACT}

Supporters of including problems around the human genome when teaching 16-year-old schoolers and being sure of the possibility of finding accurate methods for the teaching of

\footnotetext{
${ }^{1}$ Universdidad de Antioquia.
} 
Bio - grafía. Escritos sobre la Biología y su Enseñanza. ISSN 2027-1034

Edición Extraordinaria. p.p. $700-710$

Memorias del IX Encuentro Nacional de Experiencias en Enseñanza de la Biología y la

Educación Ambiental. IV Congreso Nacional de Investigación en Enseñanza de la Biología.

it, we stand out the importance of the interaction of tenth level schoolers with their teachers and mates in building up cognitive abilities and, more specifically argumentative strategies which will permit the critical use of acquired knowledge.

We implemented pedagogical, with which we intend to cheer a Meaningful Critical Learning in our students all through the arguments that they construct by themselves. We pay, hence, main attention to the statements inserted into the aural speech which emerge in the setting of different situations which are part of the pedagogical proposal.

In this sense, the statements and sequences of them are the aim of this analysis and can lead us to an approach, by students, to the Meaningful Critical Learning. We began with them by staring at the Toulminiano model elements that students incorporate into their argumentations when they make them. Right after that, we pay careful attention to those statements in which we can identify epistemological matters that, are tended to be reductionist or holistic, that students use when around the Human Genome.

\section{KEYWORDS}

Meaningful Critical Learning, human genome, argumentation, reductionist trend, holistic trend, subject social trend.

\section{INTRODUCCIÓN}

La inclusión de la enseñanza de la genética en las propuestas curriculares para jóvenes menores de 16 años es reciente, data aproximadamente de los años 70s, específicamente en países como Gran Bretaña, Estados Unidos y España. Al respecto Bugallo (1995) resalta que autores como Lawson (1983); Mitchell y Lawson (1988), entre otros, están en contra de la incorporación de los temas de genética en el currículo; una posición que sustentan en teorías piagetianas sobre las demandas cognitivas para la resolución de los problemas de esta temática disciplinar. Otros autores partidarios de la inclusión en el currículo para menores de 16 años, tales como Shayer (1974); Deadman y Kelly (1978); Smith (1991) y Stewart (1982) destacan la importancia social y cientifica de los temas y la factibilidad de encontrar métodos apropiados para su enseñanza en estos niveles educativos.

En relación con este dilema, concordamos con quienes están a favor de la inclusión de problemáticas relacionadas con la genética en los currículos para jóvenes entre 12 y 16 años. Esta opción la fundamentamos desde una perspectiva vigotskiana del aprendizaje; es decir, aceptamos el reto de contribuir con la enseñanza al desarrollo cognitivo de los estudiantes.

Jiménez-Aleixandre (2003), señala que la dinámica de las clases debe corresponder con la esencia del trabajo científico, por tanto debe girar en torno a la resolución de problemas específicamente de los problemas auténticos; es decir, aquellos problemas que son 


\title{
Bio - grafía. Escritos sobre la Biología y su Enseñanza. ISSN 2027-1034
}

Edición Extraordinaria. p.p. $700-710$

\author{
Memorias del IX Encuentro Nacional de Experiencias en Enseñanza de la Biología y la \\ Educación Ambiental. IV Congreso Nacional de Investigación en Enseñanza de la \\ Biología.
}

relevantes o de utilidad para los estudiantes. Un tipo particular de problemas auténticos son los denominados asuntos sociocientíficos -ASC-, los que de acuerdo con Sadler y Zeidler (2005) son asuntos en los cuales se hace explícita la naturaleza sociocultural del conocimiento científico y por lo tanto la mutua relación ciencia y sociedad.

Incorporar en las aulas de clase problemáticas como el Genoma Humano de corte sociocientífico, implica necesariamente tener en cuenta el papel del lenguaje y la argumentación en la construcción del conocimiento. Para comprender este papel es conveniente considerar los estudios inscritos en la línea de investigación que se ocupa de los asuntos de la enseñanza y del aprendizaje, en relación con la argumentación, por ejemplo Kuhn, 1993; Sardá y Sanmartí, 2000; Erduran, Simon y Osborne, 2004; JiménezAleixandre, 2010; Henao y Palacio, 2013, entre otros.

Consideramos que propuestas centradas en debates sobre el Genoma Humano por su carácter de asunto sociocientífico podrían constituirse en la posibilidad de incentivar los procesos de argumentación, y por tanto la flexibilidad intelectual en los jóvenes para alcanzar lo que Moreira (2005) denomina Aprendizaje Significativo Críitico, el cual reconoce la importancia de formar al joven para la crítica, para permitirle hacer parte de una cultura y, al mismo tiempo criticarla y apartarse de ella.

Por lo anterior, asumimos el reto de enseñar a argumentar y atender los propósitos de Moreira, con base en una propuesta que implica asumir la enseñanza de cuestiones relacionadas con la genética humana para identificar las relaciones entre actividades pedagógicas y aprendizaje significativo crítico.

\section{METODOLOGÍA}

Esta investigación estudia los discursos argumentativos que emergen en las discusiones que sostiene un grupo de estudiantes de décimo grado, cuando discuten sobre problemáticas alrededor del Genoma Humano en el transcurso de diferentes actividades que hacen parte de una propuesta pedagógica. Se inscribe esta en el enfoque cualitativo y se aplica bajo el método de estudio de caso, específicamente el instrumental. El énfasis del estudio es interpretativo, en el que el profesor como investigador ${ }^{2}$ interpreta en el campo para observar el desarrollo del caso, examinando su significado y reorientando sus observaciones (Stake, 1998).

En la propuesta pedagógica participan 42 estudiantes, cuya edad oscila entre los 15 y 16 años. Estos jóvenes hacen parte del grupo décimo de la Institución Educativa San Roberto Belarmino, situada en el Barrio Belén las Mercedes del Municipio de Medellín. La institución es de carácter oficial, con una población estudiantil que pertenece a estratos socio económicos 2 y 3 . Hemos elegido el grado décimo, teniendo en cuenta que en el

\footnotetext{
${ }^{2}$ Se reconocen los riesgos propios de este rol de profesor e investigador y también sus ventajas.
} 


\title{
Bio - grafía. Escritos sobre la Biología y su Enseñanza. ISSN 2027-1034
}

Edición Extraordinaria. p.p. $700-710$

\author{
Memorias del IX Encuentro Nacional de Experiencias en Enseñanza de la Biología y la \\ Educación Ambiental. IV Congreso Nacional de Investigación en Enseñanza de la \\ Biología.
}

currículo colombiano se propone el contenido disciplinar de esta investigación, igualmente porque este grupo en particular ha mostrado gran interés por la problemática.

Con este grupo realizamos una serie de actividades entre los meses de mayo y agosto de 2013, durante once encuentros; en las actividades realizamos un conversatorio pre videoforo, observación de dos videos de Discovery en la Escuela "Todo sobre el poder de los genes", una charla de un experto en medicina forense, dos foros sobre los videos vistos, un panel de expertos, presentación de la película Gattaca y un debate sobre la misma, un trabajo en grupos de discusión acerca de la Declaración Universal del Genoma Humano, un cuestionario abierto pre-debate, una consulta de una noticia sobre la clonación de células madre en humanos.

Las situaciones de aprendizaje citadas se enmarcan en el dispositivo pedagógico ciclo didáctico de enseñanza y aprendizaje, el cual se centra en preguntas problematizadoras que surgen de problemas auténticos, con lo que se plantean actividades que responden a objetivos de enseñanza. Se aplica una metodología no lineal, con secuencias didácticas que, con base en la regulación permanente, reconoce los diversos ritmos de aprendizaje de quienes aprenden (Angulo, 2001).

Las situaciones de aprendizaje fueron registradas en audio y video y seleccionamos los materiales escritos por los estudiantes, así como los episodios de acuerdo con la propuesta de unidad dialógica para el análisis de la argumentación propuesta por Leitão (2011). Con los episodios elegidos y teniendo en cuenta en ellos los enunciados de los estudiantes, se identifican las situaciones generadas por el profesor y los estudiantes. En relación con los discursos de los estudiantes, en primer lugar con base en el MAT consideramos las características que tienen algunos de sus argumentos.

Realizamos un análisis de la argumentación sustantiva, de acuerdo con lo propuesto por Henao (2010) con base en el MAT, en el que los enunciados de tipo argumentativo se pueden clasificar con base en la presencia o no de algunos de los elementos del MAT, así se toman como subcategorías cuatro rasgos de racionalidad no excluyentes, tanto categóricos, matizados, justificados como crítico- flexibles. Posteriormente y en un segundo nivel, se realiza un análisis en el que valoramos las características en las producciones argumentativas del MAT, en el que se describen datos, garantías, respaldos y refutaciones presentes en los enunciados planteados por los estudiantes.

En segundo lugar, hacemos referencia a indicios de las perspectivas epistemológicas que en relación con el genoma humano asumen los estudiantes; reconocemos por un lado la tendencia reduccionista la cual traduce el conocimiento solo a una búsqueda de causas, manifestando posiblemente desconocimiento de la complejidad respecto a la relación entre la carga genética y los factores ambientales (Marcos, 2011). Por otro lado, hay un conjunto de factores más complejo desde los cuales se reconoce que los organismos no somos simples cúmulos de moléculas o instrumentos de los genes; por el contrario que las características de los organismos están relacionadas con cuestiones socioambientales; la que Marcos (op cit) llama una tendencia holística. 
Bio - grafía. Escritos sobre la Biología y su Enseñanza. ISSN 2027-1034

Edición Extraordinaria. p.p. 700 - 710

Memorias del IX Encuentro Nacional de Experiencias en Enseñanza de la Biología y la

Educación Ambiental. IV Congreso Nacional de Investigación en Enseñanza de la Biología.

En tercer lugar, aludimos a las cuestiones de orden científico disciplinar que los estudiantes incluyen en los argumentos construidos. En esta parte nos detenemos en el análisis de los conceptos y significados que, sobre el Genoma Humano construyen los estudiantes y consideramos si son o no adecuados desde el punto de vista de la Genética.

En relación con el aprendizaje significativo crítico se plantea una estrategia pedagógica que invita, como lo propone Morerira (2005) a que los estudiantes apropien de manera crítica los desarrollos científicos y tecnológicos, para ser capaces de vivir en una sociedad de grandes y rápidos cambios de tecnologías y conceptos. Se aplican principios que facilitan este tipo de aprendizaje como aprender/enseñar preguntas en lugar de respuestas; aprender a partir de distintos materiales educativos; aprender que el lenguaje está totalmente involucrado en los intentos humanos de percibir la realidad; el significado está en las personas; cuanto más limitado sea el sistema de símbolos- lenguaje-, menos será capaz el estudiante de ver el mundo y la no utilización de la pizarra.

\section{RESULTADOS Y DISCUSIÓN}

Nuestro análisis se enfoca en los discursos de los estudiantes en el despliegue de las diferentes actividades pedagógicas, por lo tanto consideramos en un primer momento algunas de las características de los argumentos que ellos construyen, luego hacemos referencia a indicios de las perspectivas epistemológicas que en relación con el genoma humano asumen los estudiantes y tercero, aludimos a las cuestiones de orden científico disciplinar que incluyen en sus argumentos.

Respecto a los argumentos que construyen los estudiantes y los procesos epistémicos que les son inherentes, consideramos las características que tienen algunos de los argumentos de los estudiantes y las identificamos con base en el $\mathrm{MAT}^{3}$; con base en lo anterior analizamos enunciados teniendo en cuenta el contexto en relación con los discursos del profesor y los de sus compañeros, así: el profesor toma como referente la visión de un científico, y plantea la siguiente cuestión:

Marcos, un genetista, en el 2011 resalta la visión que se generó a partir de los hallazgos del proyecto genoma humano: "si todo está en los genes entonces conozcamos exhaustivamente los nuestros y sabremos todo lo necesario para manejar la vida humana" ¿ustedes estarían de acuerdo con esa visión, o no están de acuerdo y por qué?

Al respecto Camila construye un argumento, en el que identificamos algunos elementos de la propuesta toulminiana

\footnotetext{
${ }^{3}$ Modelo argumental de Toulmin
} 
Bio - grafía. Escritos sobre la Biología y su Enseñanza. ISSN 2027-1034

Edición Extraordinaria. p.p. $700-710$

Memorias del IX Encuentro Nacional de Experiencias en Enseñanza de la Biología y la Educación Ambiental. IV Congreso Nacional de Investigación en Enseñanza de la Biología.

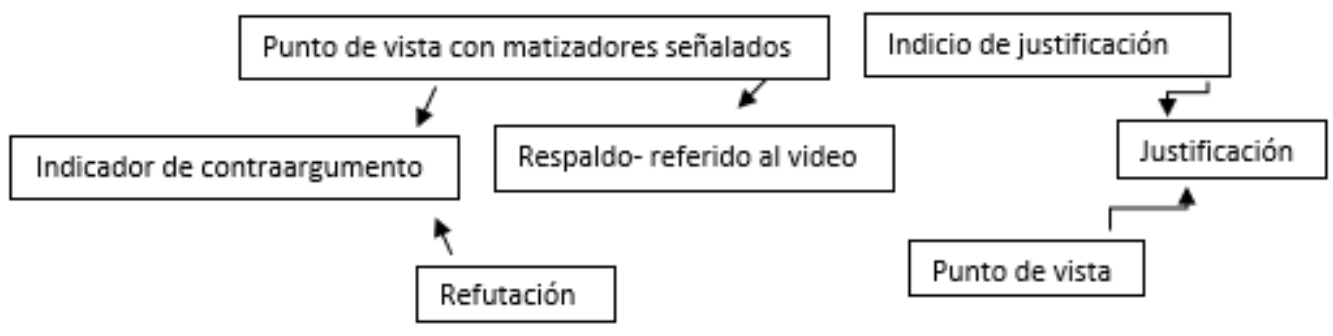

Pues no estoy muy de acuerdo, porque digamos tú podrías manejar alguna parte del cuerpo, pero también tienes sentimientos, que como su ser espiritual pues no se podrían manejar.

Este enunciado presenta rasgos de una racionalidad sustantiva, dado que presenta una justificación pertinente y coherente con la posición asumida, en el sentido en que en su punto de vista - que matiza por medio de cualificadores modales como "Pues no estoy muy (...)"-, plantea una dualidad, en la que considera que hay características que son manejables desde lo genético, mientras que otras no, lo cual justifica diciendo que hay partes manejables que se refieren a cuestiones del orden físico, no así con los que tienen que ver con los sentimientos y la espiritualidad; ambas cuestiones remiten a determinantes. Es de aclarar que en este caso, el "pero" que parecería anteceder a una refutación, une las dos partes de la justificación. Al respecto, Yensi contra argumenta a Camila diciendo:

Yo no estoy de acuerdo con Camila, porque según lo que nosotros veíamos, hay unas condiciones o algo que alimenta el cerebro, usted puede querer más al peligro pues porque tiene más adrenalina, todo tiene que ver con los genes, ya que en el crecimiento se cambien es otra cosa, pero si nosotros podemos mirar realmente son los genes.

El enunciado presenta un punto de vista que se respalda en informaciones que se presentan en el video ${ }^{4}$. La estudiante reconoce posibles acontecimientos que pueden hacer que cambien los comportamientos, probablemente se refiere a la interacción entre la producción de hormonas como la adrenalina y una respuesta asociada a condiciones del peligro.

Podemos decir que este enunciado, aunque es justificado, presenta rasgos de racionalidad categóricos, dada la manera en que reitera que son los genes los que dirigen la información y determinan un comportamiento; no obstante, a pesar de que lo reitera, incluye una refutación - a pesar de que en ésta deja leer una imprecisión conceptual en la forma como se expresa, debido a que no explicita con claridad qué es lo que cambia con el crecimiento.

\footnotetext{
${ }^{4}$ Resaltamos que antes de esta conversación los estudiantes habían visto el video "todo sobre el poder de los Genes"
} 
Bio - grafía. Escritos sobre la Biología y su Enseñanza. ISSN 2027-1034

Edición Extraordinaria. p.p. $700-710$

Memorias del IX Encuentro Nacional de Experiencias en Enseñanza de la Biología y la Educación Ambiental. IV Congreso Nacional de Investigación en Enseñanza de la Biología.

En cuanto a las perspectivas epistemológicas en las que se inscriben los argumentos que construyen los estudiantes con tendencias reduccionistas Identificamos a continuación algunos de los enunciados, en los que las relaciones se deducen al binomio causa- efecto. Esa relación, encontramos que tiene dos tendencias respecto a las causas, la primera es la de los genes como única causa de cómo somos y de la manera de pensar, de ser, actuar y de comportarnos, y la segunda tendencia considera a Dios, que es quien fija el destino y conoce previamente las decisiones humanas. (Ávila, 2008), por ejemplo:

En el contexto del primer encuentro exploratorio, se cuestiona acerca de si las características -de la inteligencia y el comportamiento-, son o no heredadas; luego de una serie de discusiones entre Carlos, Yensi y Andrés, y en las que el profesor trata de mantener vivo el debate, Andrés argumenta:

"Exacto. Vienen De Dios, si pues Dios es el que decide como es uno y como lo forma en su aspecto".

Este enunciado muestra una visión con una tendencia reduccionista de tipo religioso, en la que no da pie a contraargumentos y manifiesta reconocer la creación puesta en manos de un ser supremo.

Enunciados con tendencia Holística; resaltamos aquí algunos enunciados que con esta tendencia plantean los estudiantes, durante el primer encuentro, se cuestiona acerca de lo que puede ocurrir si el hombre llega a conocer toda la información genética que tiene; al respecto Yensi considera:

"A mí me parece que nosotros comenzaríamos a jugar un papel de Dios, comenzaríamos simplemente a dañar las cosas alrededor nuestro para nuestra conveniencia, simplemente para sentirnos cómodos. Pero nosotros no podríamos llegar a ese punto, porque nuestro entorno es lo que a nosotros nos hace sobrevivir, nos hace adecuarnos, nosotros debemos adecuarnos al entorno no el entorno a nosotros, porque dañaríamos un proceso que viene desde hace millones de años (...). Pero llegaríamos a un punto en el cual no habría ningún misterio, que a uno realmente lo haría como pensar o soñar en un mañana, porque ya todo sería tan perfecto que entonces no habría nada para descubrir"

A pesar de que Yensi comienza su argumento con un corte reduccionista religioso, prosigue planteando una tendencia holística, en la incluye principios de ecología humana y toma postura contra visiones antropocéntricas, en tanto reconoce la necesidad de adecuarnos al entorno y no el entorno a nosotros; finaliza dando aportes con visiones futuristas, al criticar el perfeccionismo que ello genera.

Reconocemos que en los enunciados se mantiene una marcada aceptación a la manipulación genética en humanos, principalmente cuando las soluciones de dicha manipulación, se dirijan a casos personales que redunden en su propio beneficio; con lo que se deja ver una perspectiva en los jóvenes respecto a cómo se leen culturalmente, es decir cómo son afectados o cómo se ven ante los otros. 
Bio - grafía. Escritos sobre la Biología y su Enseñanza. ISSN 2027-1034

Edición Extraordinaria. p.p. $700-710$

Memorias del IX Encuentro Nacional de Experiencias en Enseñanza de la Biología y la

Educación Ambiental. IV Congreso Nacional de Investigación en Enseñanza de la Biología.

Respecto a los significados que construyen los estudiantes sobre el genoma humano y los conceptos que le son correlativos nos detenemos en el análisis de los significados que sobre el Genoma Humano y otros conceptos construyen los estudiantes; resaltamos en ese caso un enunciado que hace posible inferir el uso inapropiado o no, de algunos conceptos en torno al genoma humano:

Yensi, al ser cuestionada acerca de cuáles cree que sean los aspectos que aportan a características como la inteligencia y el comportamiento de los seres humanos, responde:

"yo creo que eso tiene que ver con los datos que tienen los genes, los que vienen de los padres, porque ciertamente existe ese gen de inteligencia que se puede tener, porque si un gen formula o crea violencia en el ser humano, es un gen social, ¿sí o no?, bueno pues sí, de las personas violentas. Entonces también hay un gen que promueve la inteligencia en una persona, que la persona no lo sepa, pero que lo pudo haber heredado por alguno de sus padres".

A pesar de que creemos que este cuestionamiento es poco apropiado desde lo disciplinar, consideramos que Yensi manifiesta confusiones marcadas, al plantear relaciones como "un gen social", lo que puede traer también problemas al diferenciar los factores heredados genéticamente a los comportamientos que se aprenden de los padres.

\section{CONCLUSIONES}

Con base en los hallazgos, reconocemos los aportes a los procesos de desarrollo potencial propuestos por Vigotsky (1978), en el sentido en que ocurre una constante interacción social entre el profesor, los estudiantes y sus pares; al respecto es importante valorar la contribución de dicha interacción a la formulación de preguntas por parte del profesor y estudiantes, como un indicio de aprendizaje significativo crítico. En este sentido consideramos que en esta propuesta se presenta una argumentación sustantiva, en tanto los estudiantes incluyen elementos del modelo de Toulmin, esto es, incorporan justificaciones, matizaciones y respaldos; sustentan con datos o garantías, y evocan como respaldos los conocimientos y algunas informaciones que han apropiado de diferentes fuentes.

Respecto a los elementos incluidos reconocemos que son poco frecuentes las refutaciones o las razones que sustentan el punto de vista contrario al propio. Si bien, no son muchos los indicios de procesos metacognitivos, específicamente los que tienen que ver con posibles refutaciones o contra respuestas, identificamos contraargumentos, que indican que el estudiante tiene en cuenta lo que sus compañeros dicen respecto a su punto de vista; lo que consideramos un logro importante.

En coherencia con los proceso epistémicos, los estudiantes expresan enunciados con todos los rasgos de racionalidad -categóricos, matizados, justificados y crítico flexibles-, lo que creemos importante en el sentido que no son excluyentes unos de otros.

Respecto a los principios propuestos por Moreira, que podrían facilitar un aprendizaje significativo crítico, consideramos que la propuesta mantiene vivo el principio del 


\title{
Bio - grafía. Escritos sobre la Biología y su Enseñanza. ISSN 2027-1034
}

Edición Extraordinaria. p.p. 700 - 710

\author{
Memorias del IX Encuentro Nacional de Experiencias en Enseñanza de la Biología y la \\ Educación Ambiental. IV Congreso Nacional de Investigación en Enseñanza de la \\ Biología.
}

conocimiento como lenguaje, cuando el profesor abre la posibilidad de que los estudiantes expliciten sus formas de percibir la realidad, de expresar sus apreciaciones en su propio lenguaje, cuando se invita a argumentar y pensar de forma diferente sobre el mundo, así como cuando brinda la posibilidad de negociar significados.

Un segundo principio tiene que ver con que la práctica pedagógica no se centra en la utilización del libro de texto, se fomenta el uso de materiales como artículos científicos en los que se analizan aspectos como la clonación, la manipulación de células madre y transgénicos; el análisis crítico la Declaración Universal del Genoma Humano; consulta del periódico sobre la noticia de la clonación de células madre en humanos, entre otros materiales.

Un tercer principio, alude a la no utilización de la pizarra como expresión de la trasmisión dogmática; al respecto podemos reconocer que en la propuesta se permite la participación activa de los estudiantes, mediante el uso de actividades colaborativas, como el análisis de documentos en grupos, discusiones, paneles de expertos, debates y foros de los videos presentados.

Respecto al cuarto principio, en el que se alude a una incertidumbre del conocimiento, consideramos que aunque no son muy frecuentes las refutaciones, resaltamos los rasgos de racionalidad crítico- flexibles, que se manifiestan cuando en sus enunciados los estudiantes se separan de sus afectos y reconocen en algunos casos que por ejemplo la manipulación genética limitar su aplicación.

El quinto principio de la interacción social y del cuestionamiento, se manifiesta en la propuesta cuando mediante el intercambio de preguntas se mantiene una constante negociación de significados entre los estudiantes y el profesor; al respecto, reconocemos en el profesor la necesidad de mantener abierto el debate con cuestionamientos constantes y darle importancia a los conocimientos de los estudiantes.

En relación con los significados del genoma humano y las consideraciones de orden sociocultural que en esos significados se incluyen, encontramos que los discursos de los estudiantes presentan una mayor tendencia reduccionista, en la que hacen presente una visión religiosa. Sin embargo, reconocemos que sus argumentos están permeados por el qué dirán, cómo se verán, qué tanto los afecta; identificando las implicaciones personales y sociales que podría traer la manipulación genética.

Lo anterior nos invita a sugerir a otras propuestas de enseñanza, que no solo consideren cuestionamientos acerca de los aspectos de manipulación del genoma humano, sino que profundicen en las discusiones relacionadas con la incidencia de factores socioambientales, lo que podría incentivar un mayor uso de conceptos y modelos explicativos sobre el genoma humano. 
Bio - grafía. Escritos sobre la Biología y su Enseñanza. ISSN 2027-1034

Edición Extraordinaria. p.p. $700-710$

Memorias del IX Encuentro Nacional de Experiencias en Enseñanza de la Biología y la Educación Ambiental. IV Congreso Nacional de Investigación en Enseñanza de la Biología.

\section{BIBLIOGRAFÍA}

Angulo Delgado, F (2001). Un modelo didáctico para la formación inicial del profesorado de ciencias naturales. En Http/docencia.udea.edu.co/revista_icfes/art/3.doc. Acceso en: Diciembre 26 de 2013.

Bugallo Rodríguez, A. (1995). La didáctica de la genética: revisión bibliográfica. Enseñanza de las Ciencias, Vol. 13, pp. 379-385.

Henao, S, Berta Lucila y Stipcich, Maria Silvia. (2008). Educación en ciencias y argumentación: la perspectiva de Toulmin como posible respuesta a las demandas y desafíos contemporáneos para la enseñanza de las Ciencias Experimentales. Revista electrónica de Enseñanza de las ciencias, vol. 7 Número 1

Henao, S, Berta Lucila y Palacio, M. Luz Victoria. (2013). La argumentación en la clase de ciencias. En A. Romero, B. L. Henao, J. F. Barros (Eds), Formación científica en y para la civilidad: desafíos y posibilidades de la educación en ciencias, (pp. 23-67). Medellín: Artes y letras S.A.S.

Jiménez-Aleixandre, M. P. y Díaz de Bustamante, Joaquín. (2003). Discurso de aula y argumentación en la clase de ciencias: cuestiones teóricas y metodológicas. Enseñanza de las ciencias, 21 (3), pp. 359-370.

Leitão, Selma. (2011). Argumentacão na scola: O conhecimento em construção. En M. Selma, D. María (Comps), O lugar da argumentação do conhecimento em sala de aula (pp 13-46). Campinas, SP: Ponte Editores.

Moreira, Marco Antonio. (2005). Aprendizaje Significativo Crítico, Versión de la conferencia dictada en el III Encuentro Internacional sobre Aprendizaje Significativo, Lisboa (Peniche), 11 a 15 de septiembre de 2000. En las Actas del III Encuentro Internacional sobre Aprendizaje Significativo, pp. 33-45.Porto Alegre, RS, Brasil.

Sadler, T. D y Zeidler, D. L. (2005). Patterns of informal reasoning in the context of sociocientific decision making journal of reseach. Science teaching. 42, 112-138.

Shayer, M. (1974).Conceptual demand in the O-leve1 Nuffield.biology course. school science review, Vol. 56 (.195), PP.381- 388.

Smith, M.U. Sims, O.S. (1992). Cognitive development, genetics problem solving, and genetics instruction: A critical review. Journal of Research in Science Teaching, Vol. 29(7), pp. 701-713.

Stake, Robert E. (1998).Investigación con estudio de caso, Madrid España: Ediciones Morata.

Toulmin, Stephen E. (1977). La comprensión humana: El uso colectivo y la evolución de los conceptos. Madrid: Alianza.

Toulmin, Stephen E. (2003). The Uses of Argument, Updated edition, Cambridge University Press 1958, pp. 70. 
Bio - grafía. Escritos sobre la Biología y su Enseñanza. ISSN 2027-1034

Edición Extraordinaria. p.p. 700 - 710

Memorias del IX Encuentro Nacional de Experiencias en Enseñanza de la Biología y la Educación Ambiental. IV Congreso Nacional de Investigación en Enseñanza de la Biología.

Vigotsky, L. (1978). Interaction between learning and development. From Mind and Society. En G. Mary, C. Michael (Eds). Readings on the developmen of children (pp 7991). Cambridge, MA: Harvard University Press. 